\title{
Fetal Down syndrome screening models for developing countries; Part II: Cost-benefit analysis
}

\author{
Chanane Wanapirak', Piyaluk Buddhawongsa², Woraluck Himakalasa², Auttapan Sarnwong ${ }^{2}$ and \\ Theera Tongsong ${ }^{1 *}$ (D)
}

\begin{abstract}
Background: To identify the most cost-beneficial model as a national policy of screening and diagnosis of fetal Down syndrome (DS) in developing countries.

Methods: Cost-benefit analysis (CBA) was performed based on the effectiveness and probabilities derived from a large prospective study on MSS (maternal serum screening) among Thai population. Various models including maternal age alone, STS (second trimester screen), I-S (independent screen: first or second trimester screen depending on the time of first visit), C-S (contingent serum screen) plus STS, maternal age with NIPS (non-invasive prenatal test), STS alone with NIPS, I-S with NIPS, C-S plus STS with NIPS, and Universal NIPS were compared.

Results: I-S with NIPS as a secondary screening was most cost-beneficial (Benefit/Cost ratio 4.28). Cost-benefit is directly related to the costs of NIPS.

Conclusion: In addition to simplicity and feasibility, I-S with expensive NIPS as a secondary screening is the most cost-beneficial method for low resource settings and should be included in universal healthcare coverage as a national policy. This study could be a model for developing countries or a guideline for international health organizations to help low resource countries, probably leading to a paradigm shift in prenatal diagnosis of fetal DS in the developing world.
\end{abstract}

Keywords: Down syndrome, Prenatal screening, Prenatal diagnosis, Cost-benefit, Developing country

\section{Background}

Prenatal screening and diagnosis of Down syndrome (DS) with maternal serum screening (MSS) has been established in developed countries [1]. However, the incidence in countries with low-resource settings has not changed much in recent years, in spite of the fact that there is more need for lower incidence in poorer countries, since DS can constitute more burdens due to the low quality of life in poor countries [2,3]. Moreover, in low resource countries, the socio-economic gap is even wider. We believe that economic inequality results in health inequality. In this regard, the expensive but more effective non-invasive prenatal screen (NIPS) has been

\footnotetext{
* Correspondence: theera.t@cmu.ac.th

${ }^{1}$ Department of Obstetrics and Gynecology, Faculty of Medicine, Chiang Mai University, Chiang Mai 50200, Thailand

Full list of author information is available at the end of the article
}

accepted by wealthy couples but the poor do not have the opportunity to benefit from it. The only way to overcome this problem is to include cost-benefit screening in universal health care coverage as a national policy. In Thailand, we are considering the implementation of DS screening for all women as a national policy free of charge. However, the most cost-beneficial model is not known, especially in developing countries. Additionally, the studies on the cost-benefit of such strategies are mostly based on simulations of hypothetical cohort instead of testing on real situations that are varied among geographical and racial groups. Many cost-benefit studies [4-7] relied on the western data of MSS developed for western population, but its efficacy is very different from that used in other parts of the world. Moreover, CBA (cost-benefit analysis) in previous studies were based on assumption that all women were assumed to

(c) The Author(s). 2019 Open Access This article is distributed under the terms of the Creative Commons Attribution 4.0 International License (http://creativecommons.org/licenses/by/4.0/), which permits unrestricted use, distribution, and 
attend prenatal care in the first trimester. This is not true in real practice. To yield the most reliable results of $\mathrm{CBA}$, the input variables must be most accurate. Therefore, we conducted this CBA based on the effectiveness of various models of primary screenings and real probabilities of various events derived from our own large prospective project [8]. This study was done to determine the best model for developing countries based on feasibility, simplicity and cost-benefit, so as to be considered in the universal health care coverage. Accordingly, this study did not include the techniques that are not practicable in low resource settings, such as NT, which needs expertise and is not widely available; integrated MSS test, which needs two screenings and the costs are double. However, NIPS as a secondary screening test might be cost-beneficial even in poor countries if the primary screen (MSS) is very effective with a low false positive rate (a small number of amniocenteses). It is more feasible to make NIPS available all over a country than amniocentesis, with a large number of chromosome laboratories. Accordingly, we performed CBA for several strategies, both when combined with NIPS and when not combined, to identify the most cost-beneficial model as a national policy of screening and diagnosis of fetal Down syndrome (DS) in developing countries.

\section{Methods}

This study was cost-benefit analysis (CBA) which was conducted with ethical approval by the institutional review board, as the second part of our previous study [8], which was prospectively conducted on 41,924 pregnancies in the northern part of Thailand, including $33 \mathrm{com}$ munity hospitals. CBA was based on the effectiveness of MSS and probabilities of various events derived from the previous study [8] and was performed from both societal and government perspectives. Probabilities and costs were applied to a hypothetical cohort of 800,000 pregnant women, representing the estimated annual number of pregnancies in Thailand. This CBA was performed using decision tree for 10 models as follows: 1) Reference situation (Base case): No prenatal screening and no amniocentesis (invasive prenatal testing); 2) Maternal age alone: Advanced maternal age ( $\geq 35$ years) was classified as high risk and was offered amniocentesis; 3) Maternal age with NIPS: Advanced maternal age $(\geq 35$ years) was classified as high risk and offered NIPS. If NIPS was positive, amniocentesis was offered; 4) STS (second trimester screening) alone: Screening all women in the second trimester (15-20 weeks of gestation) and amniocentesis was offered in case of high risk serum markers; 5) STS with NIPS: Screening all women in the second trimester and NIPS was offered in case of high risk serum markers and amniocentesis was performed if NIPS was positive; 6) Independent screen (I-S): Women seen in the first trimester (9-14 weeks) were screened with FTS (first trimester screening) and those seen in the second trimester (15-20 weeks) were screened with STS. The women at high risk either by FTS or STS were offered amniocentesis; 7) I-S with NIPS: The same as no.6; but the high risk cases either by FTS or STS were offered NIPS and then amniocentesis in case of positive NIPS; 8) C-S (contingent serum screen) plus STS: Women seen in the first trimester (9-14 weeks) were screened with FTS and were classified as high risk (risk $>1: 30$ ) indicated for amniocentesis, intermediate risk (risk between 1:30-1:1500) indicated for STS and reclassified risk into low or high risk $(>1: 250)$ by all serum markers, and low risk (risk < 1500) needed no further tests. The women seen in the second trimester (15-20 weeks) were screened with STS mentioned above (no. 4); 9) C-S plus STS, with NIPS: The same as no. 8; but the high risk cases were offered NIPS instead and amniocentesis in cases of positive NIPS; 10) Universal NIPS: All pregnant women before 20 weeks of gestation were offered NIPS and amniocentesis in cases of positive NIPS.

The CBA was based on the concept in Fig. 1 which compared the costs and outcomes of the models in money units. The costs included medical cost, family and relative costs and productivity $(\mathrm{C} 1+\mathrm{C} 2+\mathrm{C} 3)$. They also included a number of DS secondary to false negative of the screening tests, non-acceptance of pregnancy termination of fetal DS and productivity of normal fetuses ending-up with fetal loss caused by amniocentesis. The benefits of the model included the sum of willingness to pay money to avoid having a DS baby and costs saved

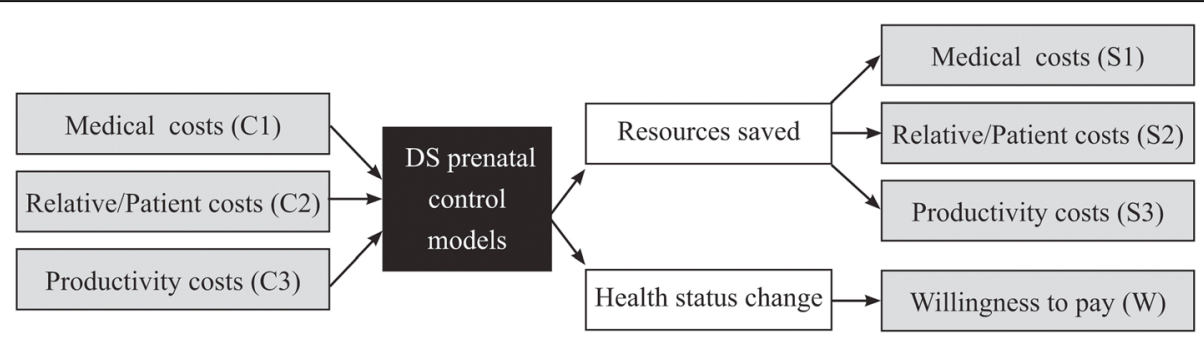

Fig. 1 Components of economic calculation of Down syndrome (DS) control models 
from the avoidance of DS (S1 + S2 + S3: direct and indirect life time costs and productivity). Cost-benefit calculation was expressed as incremental benefit-to-cost ratio ( $\Delta$ benefit / $\Delta$ cost) and incremental benefit-to-cost difference ( $\Delta$ benefit $-\Delta$ cost), whereas $\Delta$ benefit is the benefit of any situation minus the benefit in the reference situation or without any screening and $\Delta$ cost is the cost of any situation minus the cost in the reference situation.

Direct medical cost included screening tests and prenatal diagnosis (serum markers, cytogenetic lab, counseling and termination of pregnancy) and cost of taking care of DS child (physical program, treatment of complications, stimulating/promoting development). Direct non-medical cost included accommodation, meals, commuting of the patients and relatives during doctor visits and informal care of DS child. Indirect cost included productivity of: 1) the patients and relatives during doctor visits, 2) normal child terminated due to false positive tests, and 3) the relatives of taking care of the DS child. Costs from societal perspective included all items mentioned above while costs from governmental perspective included only direct medical cost. Probabilities of events and variables in effectiveness of screening tests and prenatal diagnoses: sensitivities and specificities (using risk cut-off 1:250) were derived from the study in the same population [8]. The costs of screening and prenatal diagnosis were assessed from our centers with micro-costing analysis. Direct and indirect costs of taking care of DS were derived from wellestablished publications [2, 9-11], with conversion to be equivalent to the Thai costs of living. All costs were adjusted to the costs in 2015 with consumer price index (CPI). The benefits consisting of the costs saved by the avoidance of new cases of DS and benefits in health outcomes were assessed from "willingness to pay (WTP) survey". WTP was based on the interview (in Thai language) of women aged 25-45 years, in the year 2014 with the following question. "In the scenario that you are pregnant and your baby is affected by Down syndrome, what is the highest payment you are willing to make to avert the scenario? The payment you have to make once in six months. This is in the condition that you are willing to give birth to a Down's baby and the government is responsible for all costs of living such as cost of taking care, illness treatment, nursing etc." Then the willingness-to-pay was evaluated with bidding or bargaining format. In this study the interviewer offered the starting point of 5000 to 300,000 Thai baht to reduce biases which might occur during bargaining. The uncertainty analysis was performed using one-way and probabilistic sensitivity analyses. The CBA was analyzed using A software package (TreeAge Pro 2009, TreeAge Inc., Williams-town, MA, USA).

\section{Results}

We based the CBA on 41,924 screens with a risk cutoff of 1:250, both the model performance and event probabilities as summarized in Tables 1 and 2. The accuracy of NIPS (99.0\%) was based on previous studies [12] and the acceptance rate $(99.0 \%$, in case of free of charge) was assumed based on the acceptance of MSS in our previous study [8]. Costs screening tests used in the CBA were calculated by micro-costing, representing costs in Thailand in the year 2015. However, the life-time cost for taking care of a DS child among Thai population with reliable and comprehensive analysis was not available. Thus, we used the cost from the western well-established data with being converted to cost equivalent to Thai cost of living using purchasing

Table 1 Probabilities of the events used in the simulations [8]

\begin{tabular}{lll}
\hline Variables & Distri-bution & Mean \\
\hline Prevalence of women attending antenatal care in the first trimester & normal & beta \\
Prevalence of DS at 16 weeks of gestation in women of $<35$ years of age & beta & 0.0016 \\
Prevalence of DS at 16 weeks of gestation in women of $\geq 35$ years of age & beta & 0.0057 \\
Prevalence of DS at 16 weeks of gestation in women of all age & beta & 0.0018 \\
Prevalence of DS in women of all age & beta & 0.0018 \\
MSS uptake among women of all age & beta \\
Amniocetesis uptake among women of all age & beta \\
Spontaneous abortion of DS fetuses at 10 weeks of gestation & beta \\
in women of all age & beta \\
Spontaneous abortion of DS fetuses at 16 weeks of gestation & normal \\
in women of all ages & beta & 0.9557 \\
Spontaneous abortion of DS fetuses in women of all age & beta \\
Termination of pregnancy in case of +ve amniocentesis & 0.2713 \\
Amniocentesis-related fetal loss & 0.2920 \\
NIPS uptake (assumption for free of charge) & 0.9500 \\
\hline
\end{tabular}


Table 2 Sensitivity and specificity of prenatal screening test and diagnostic test used in the simulations [8]

\begin{tabular}{llll}
\hline Screening / Diagnostic Tests & Type of distribution & Sensitivity & Specificity \\
\hline FTS & beta & 0.792 & 0.932 \\
STS (Triple screen) & beta & 0.762 & 0.908 \\
Independent screen (I-S) & beta & 0.784 & 0.925 \\
Contingent screen (C-S plus STS) & beta & 0.849 & 0.923 \\
NIPS [12] & beta & 0.990 & 0.980 \\
\hline
\end{tabular}

power parity conversion factor (Consumer Price Index of THAILAND YEAR 2019; conversion factor LCU per international $\$=13.04)$. The cost of NIPS was based on Thai NIPS which was the lowest price in Thailand in 2019. The willingness to pay (WTP) to avert having DS child in women of all age was based on the survey study among Thai population. Rates of acceptance were based on the assumption that various prenatal screening tests or diagnostic tests were free of charge, according to health coverage by the national policy. The probabilities of various events and cost used in the CBA are summarized and presented in Table 1, 2 and 3. All models for CBA were based on Thai reference range (TRR). Probabilities and costs were applied to a hypothetical cohort of 800,000 pregnant women, representing the estimated annual number of pregnancies in Thailand. This CBA was performed using decision tree for 10 models as stated in the "Methods" section.

The CBA used decision-analytic modeling as an example in Fig. 2, to determine the outcomes, total costs, relative costs, cost-benefit difference and ratio, and events of different models are presented in Table 3 and 4. It directly compares current clinical practice in most parts of Thailand, no screening as the base case. From societal perspective, I-S with NIPS would be most cost-beneficial when the cost of NIPS $\$ 416.86$ or less, giving $\mathrm{B} / \mathrm{C}$ ratio of 4.28. If NIPS is more expensive, C-S plus STS (without NIPS) would be most cost-beneficial (Table 5, Fig. 3). However, its detection rate was slightly lower when compared with the C-S plus STS model. The most costbeneficial model, from governmental perspective, was the independent screening without NIPS, giving $\mathrm{B} / \mathrm{C}$ ratio of 2.30. Cost-benefit is directly related to the costs of NIPS (Table 6). I-S with NIPS gave the $\mathrm{B} / \mathrm{C}$ ratio of 4.84 if the cost of NIPS was decreased to $\$ 277$ (This is Thai NIPS cost in 2019).

If 60,50 and $40 \%$ of women first present in the first trimester, sensitivity analysis for societal perspective still shows that I-S with NIPS is most costbeneficial with $\mathrm{B} / \mathrm{C}$ ratio of $4.15,3.87$ and 3.59 , respectively. (not shown in Table).

Table 3 Costs used in the simulations (expressed in USD, adjusted value for the year 2019)

\begin{tabular}{|c|c|c|c|c|c|c|}
\hline Costs & $\begin{array}{l}\text { Type of } \\
\text { distribution }\end{array}$ & $\begin{array}{l}\text { Cost from government } \\
\text { perspectives (direct } \\
\text { medical) }\end{array}$ & $\begin{array}{l}\text { Direct non-medical cost } \\
\text { of a woman and } \\
\text { relatives }\end{array}$ & $\begin{array}{l}\text { Indirect } \\
\text { cost }\end{array}$ & $\begin{array}{l}\text { Cost from } \\
\text { societal } \\
\text { perspective }\end{array}$ & References \\
\hline FTS (first trimester screen) & gamma & 30.63 & 58.02 & & 88.65 & \multirow{6}{*}{$\begin{array}{l}\text { Calculated by } \\
\text { micro-costing }\end{array}$} \\
\hline STS (second trimester screen) & gamma & 33.65 & 58.02 & & 91.67 & \\
\hline $\begin{array}{l}\text { Amniocentesis and chromosome } \\
\text { study \& counseling }\end{array}$ & gamma & 141.56 & 58.02 & & 199.58 & \\
\hline Intended termination of pregnancy & gamma & 77.31 & - & & 77.31 & \\
\hline Vaginal delivery & gamma & 66.50 & - & & 66.50 & \\
\hline Cesarean delivery & gamma & 245.64 & - & & 245.64 & \\
\hline NIPS & gamma & 416.86 & 58.02 & & 474.88 & Thai NIPS \\
\hline Lifetime costs of taking care of DS & gamma & $103,251.46$ & & $479,892.65$ & 583,144 & $\operatorname{Ref}[2,9-11]^{a}$ \\
\hline $\begin{array}{l}\text { Indirect costs of normal child (in case } \\
\text { of termination due to false positive) }\end{array}$ & gamma & & & 44,229 & 44,229 & Ref [3] \\
\hline $\begin{array}{l}\text { WTP to avert having DS child in } \\
\text { women of all age }\end{array}$ & gamma & 1945 & & & 1945 & Questionnaire \\
\hline \multicolumn{7}{|c|}{$\begin{array}{l}\text { a This study transfers the lifetime costs of Down syndrome children from the previous studies to measure the medical costs (ref } 11 \text { ) and indirect lifetime costs. } \\
\text { Since the information from those studies was based on samples in the United States and the studies were conducted in } 2011 \text { and } 2017 \text {, the value of transferred } \\
\text { cost applied in this study needs to be adjusted according to Thailand context and the time of valuation. The purchasing power and currency adjustment between } \\
\text { Thai and the U.S. is adjusted by the PPP conversion factor (World bank, 2019: PPP conversion factor, private consumption (LCU per international \$) Retrieved } \\
\text { October 1, 2019, from http://data.worldbank.org/indicator/PA.NUS.PRVT.PP) and the different time period is adjusted by Consumer Price Index (CPI) (Ministry of } \\
\text { Commerce, 2019: Consumer Price Index of THAILAND YEAR } 2019 \text { BASE YEAR } 2011 \text { and 2017. Retrieved October 1, 2019, from http://www.indexpr.moc.go.th/price_- } \\
\text { present/TablelndexG_region.asp?table_name=cpig_index_country\&province_code=5\&type_code=g\&check_f=i\&year_base=2560\&nyear=2562 AND Bank of } \\
\text { Thailand (2019) Historical Foreign Exchange Rates Retrieved October 1, 2019, } \\
\text { from https://www.bot.or.th/english/_layouts/application/exchangerate/exchangerateago.aspx) }\end{array}$} \\
\hline
\end{tabular}




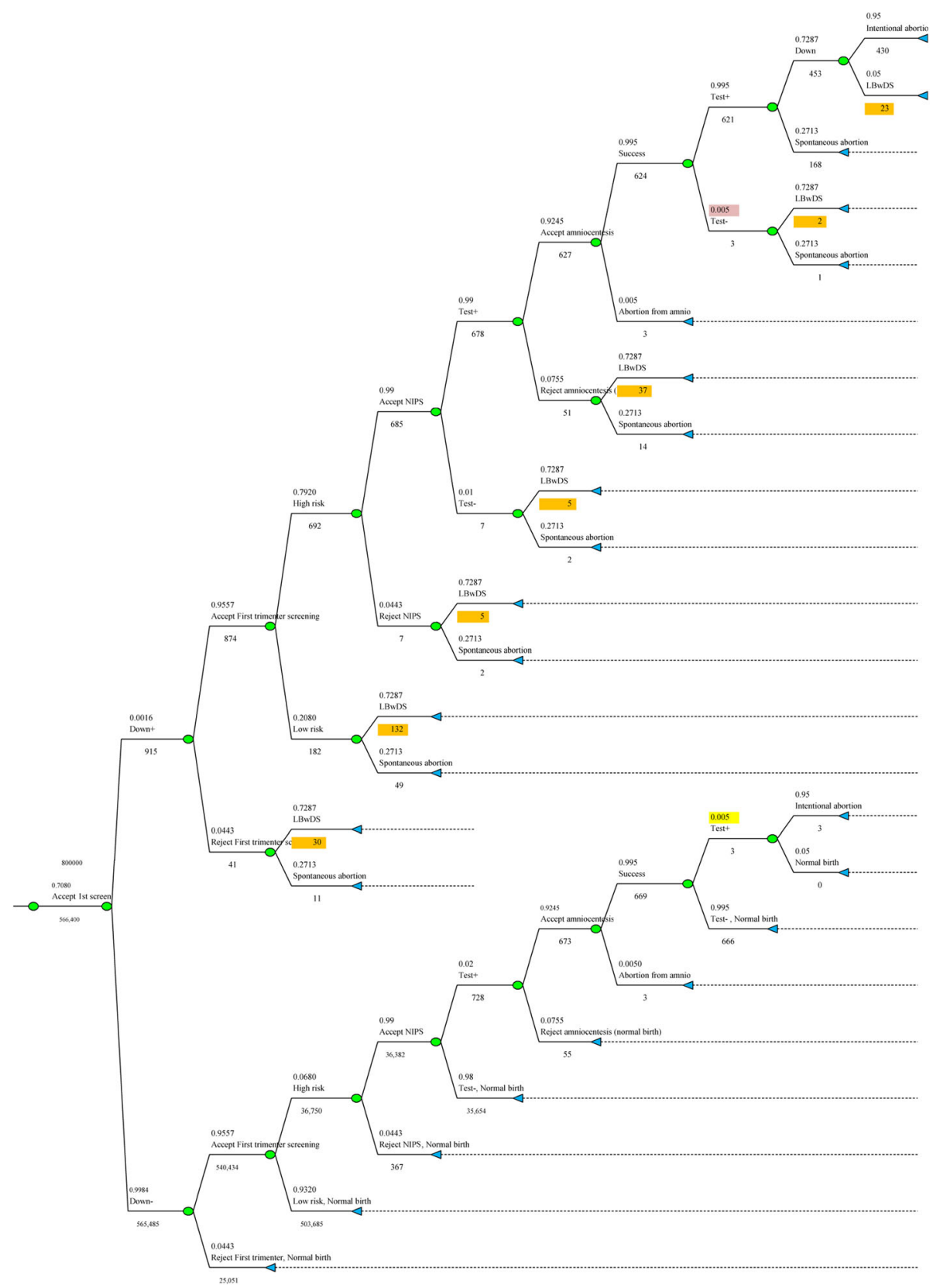

Fig. 2 An example of decision tree, FTS as a part of I-S with NIPS (Model 8), shows probability and numbers of DS and non-DS group at each step of screening which could be detected or missed from the first step of acceptance/rejection of screening through various steps to definite diagnosis. The number of cases at each step was used for cost calculation. At first step, 70.8\% of 800,000 women underwent FTS with NIPS (nearly 30\% had no screen; including some cases with DS), consisting of 915 DS and 565,485 non-DS pregnancies. Each group had branching for a further series of actions in case of positivity. For example, DS group consisted of high risk and low risk pregnancies. The low risk had no further test, though consisting of live birth DS and DS with spontaneous abortion. Nearly all high risk pregnancies accepted but some rejected NIPS; nearly all cases with +ve NIPS accepted amniocentesis in which nearly all cases had successful procedures and few had failed procedure or lab failure). Failure to detect DS could occur at any cascade; and finally not all detected DS accepted intentional abortion. Likewise, of non-DS group, false positive result could occur at any cascade, though it should not (lab error, specimen switching); intentional abortion could also occur though very rare

\section{Discussion}

The important insights gained from this study are: 1) While C-S was the most effective serum screening test, the most cost-beneficial model, from societal perspective, was I-S with NIPS, though the detection rate was slightly lower than C-S plus STS model. 2) The most costbeneficial model from governmental perspective was I-S, without NIPS. Nevertheless, as a national policy, CBA is 
Table 4 Expected events in various situations of 800,000 pregnant women in one year (see an example of decision tree for model in Fig. 2)

\begin{tabular}{|c|c|c|c|c|c|c|}
\hline \multirow[t]{2}{*}{ Situations } & \multirow{2}{*}{$\begin{array}{l}\text { No. DS } \\
\text { live births }\end{array}$} & \multirow{2}{*}{$\begin{array}{l}\text { No. of } \\
\text { spon-taneous } \\
\text { abortion }\end{array}$} & \multirow{2}{*}{$\begin{array}{l}\text { No. of } \\
\text { intention } \\
\text { termina-tion }\end{array}$} & \multicolumn{2}{|c|}{ No. of abortion due to amniocenteses } & \multirow{2}{*}{$\begin{array}{l}\text { No. of } \\
\text { amniocen-teses } \\
\text { and chromosome } \\
\text { studies }\end{array}$} \\
\hline & & & & Down + ve & Down -ve & \\
\hline 1. No screening & 1152 & 475 & - & - & - & - \\
\hline 2. Maternal age alone & 899 & 491 & 705 & 2 & 428 & 86,158 \\
\hline $\begin{array}{l}\text { 3. Second trimester } \\
\text { screen (STS) alone }\end{array}$ & 367 & 280 & 947 & 4 & 325 & 65,794 \\
\hline 4. Independent screen (I-S) & 333 & 329 & 876 & 4 & 265 & 53,827 \\
\hline First trimester screen (FTS) & 226 & 247 & 600 & 3 & 136 & 34,615 \\
\hline STS & 107 & 82 & 277 & 1 & 78 & 19,212 \\
\hline 5. C-S plus STS & 318 & 296 & 841 & 5 & 178 & 36,592 \\
\hline$C-S$ & 211 & 214 & 565 & 3 & 67 & 17,380 \\
\hline STS & 107 & 82 & 277 & 1 & 76 & 19,212 \\
\hline $\begin{array}{l}\text { 6. Maternal age } \\
\text { with NIPS }\end{array}$ & 905 & 489 & 302 & 2 & 8 & 2178 \\
\hline 7. STS alone with NIPS & 395 & 284 & 633 & 4 & 6 & 2093 \\
\hline $\begin{array}{l}\text { 8. Independent screen } \\
(I-S) \text { with NIPS }\end{array}$ & 350 & 330 & 618 & 4 & 5 & 1911 \\
\hline FTS with NIPS & 234 & 247 & 433 & 3 & 3 & 1300 \\
\hline STS with NIPS & 115 & 83 & 185 & 1 & 2 & 611 \\
\hline 9. C-S plus STS with NIPS & 354 & 323 & 619 & 4 & 3 & 1560 \\
\hline$C-S+N I P S$ & 239 & 240 & 434 & 3 & 2 & 949 \\
\hline STS + NIPS & 115 & 83 & 185 & 1 & 1 & 611 \\
\hline 10. Universal NIPS & 165 & 473 & 1051 & 7 & 73 & 16,089 \\
\hline
\end{tabular}

Table 5 Costs and benefits (USD/woman) of various models from societal and government perspective when cost of NIPS is $\$ 416.86(13,000 \mathrm{THB})$

\begin{tabular}{|c|c|c|c|c|c|c|c|c|c|c|}
\hline \multirow[t]{2}{*}{ Strategies } & \multicolumn{5}{|l|}{ Societal Perspective } & \multicolumn{5}{|c|}{ Government Perspective } \\
\hline & $\begin{array}{l}\text { Cost of screening } \\
\text { and prenatal } \\
\text { diagnosis } \\
\text { (1) }\end{array}$ & $\begin{array}{l}\text { Cost saved } \\
\text { by avoiding } \\
\text { DS births } \\
\text { (2) }\end{array}$ & $\begin{array}{l}\text { WTP } \\
\text { (3) }\end{array}$ & $\begin{array}{l}\text { Benefit-cost } \\
\text { difference } \\
\text { (4) }\end{array}$ & $\begin{array}{l}\text { Benefit- cost } \\
\text { ratio } \\
\text { (5) }\end{array}$ & $\begin{array}{l}\text { Cost of screening } \\
\text { and prenatal } \\
\text { diagnosis } \\
\text { (1) }\end{array}$ & $\begin{array}{l}\text { Cost saved } \\
\text { by avoiding } \\
\text { DS births } \\
\text { (2) }\end{array}$ & $\begin{array}{l}\text { WTP } \\
\text { (3) }\end{array}$ & $\begin{array}{l}\text { Benefit-cost } \\
\text { difference } \\
\text { (4) }\end{array}$ & $\begin{array}{l}\text { Benefit- } \\
\text { cost ratio } \\
(5)\end{array}$ \\
\hline 1. No screening & 0 & 0 & 0 & 0 & 0 & 0 & 0 & 0 & 0 & 0 \\
\hline $\begin{array}{l}\text { 2. Maternal age } \\
\text { alone }\end{array}$ & 80.0 & 184.5 & 0.7 & 105.2 & 2.32 & 18.1 & 32.7 & 0.7 & 15.3 & 1.84 \\
\hline 3. STS alone & 164.4 & 571.9 & 2.3 & 409.7 & 3.49 & 51.9 & 101.3 & 2.3 & 51.6 & 1.99 \\
\hline $\begin{array}{l}\text { 4. Independent } \\
\text { screen (I-S) }\end{array}$ & 150.9 & 597.1 & 2.4 & 448.6 & 3.97 & 47.0 & 105.7 & 2.4 & 61.1 & 2.30 \\
\hline 5.C-S plus STS & 149.4 & 607.6 & 2.4 & 460.6 & 4.08 & 48.8 & 107.6 & 2.4 & 61.2 & 2.26 \\
\hline $\begin{array}{l}\text { 6. Maternal age } \\
\text { with NIPS }\end{array}$ & 62.2 & 180.1 & 0.7 & 118.7 & 2.91 & 52.4 & 31.9 & 0.7 & -19.8 & 0.62 \\
\hline $\begin{array}{l}\text { 7. STS alone with } \\
\text { NIPS }\end{array}$ & 146.4 & 551.9 & 2.2 & 407.7 & 3.78 & 74.0 & 97.7 & 2.2 & 25.9 & 1.35 \\
\hline 8. I-S with NIPS & 137.1 & 584.9 & 2.3 & 450.1 & 4.28 & 65.8 & 103.6 & 2.3 & 40.1 & 1.61 \\
\hline $\begin{array}{l}\text { 9. C-S plus STS } \\
\text { with NIPS }\end{array}$ & 139.4 & 581.5 & 2.3 & 444.4 & 4.19 & 60.8 & 103.0 & 2.3 & 44.5 & 1.73 \\
\hline 10. Universal NIPS & 494.8 & 719.4 & 2.8 & 227.4 & 1.46 & 416.2 & 127.4 & 2.8 & -286.0 & 0.31 \\
\hline
\end{tabular}

Benefit-cost difference $=[(2+3)$ any situation $-(2+3)$ situation 1$]-[1$ any situation -1 situation 1$]$

Benefit-cost ratio $=[(2+3)$ any situation $-(2+3)$ situation 1$] /[1$ any situation -1 situation 1$]$ 


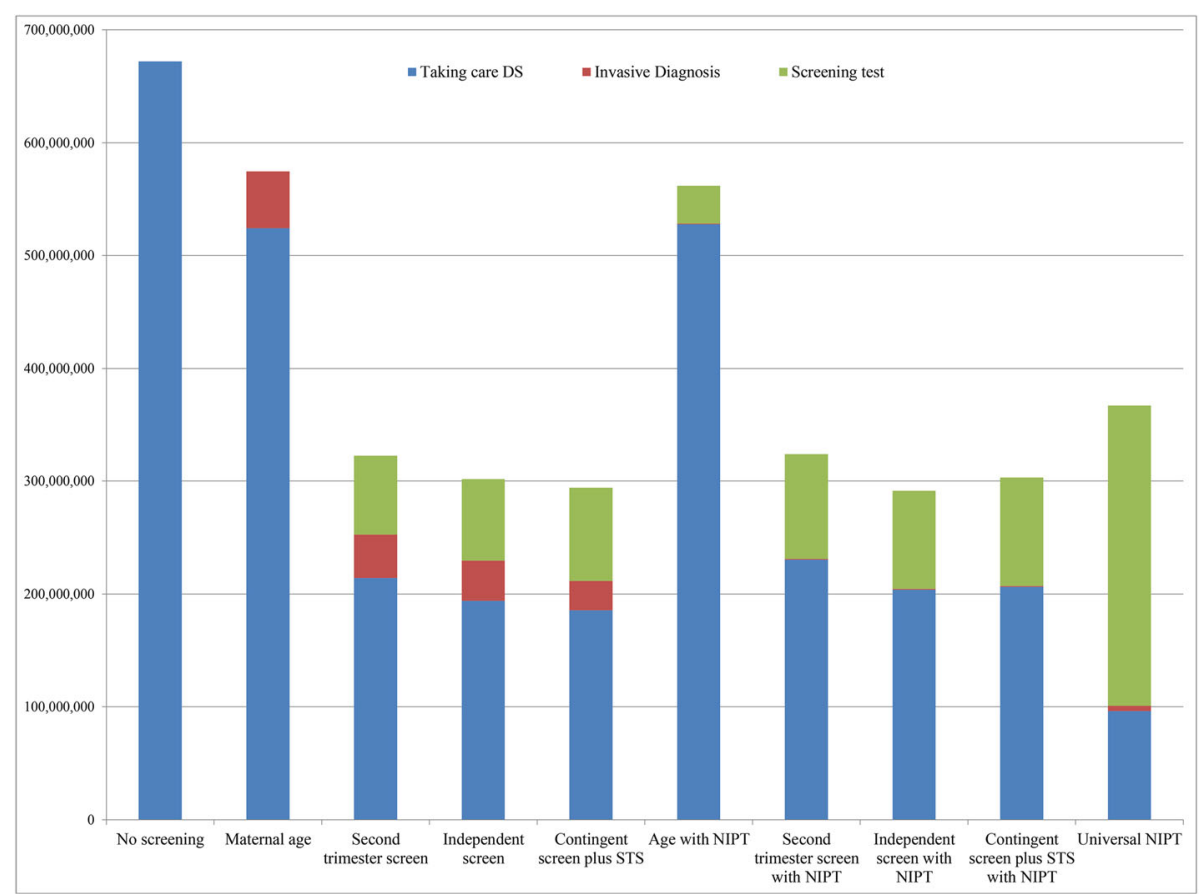

Fig. 3 Cost for each model in prenatal control of fetal Down syndrome among 800,000 pregnancies (societal perspective)

better based on societal perspective since taking care of DS child both direct and indirect costs as well as productivity loss due to amniocentesis are all societal burdens. 3) Cost-benefit is directly related to the costs of NIPS. In addition, I-S with NIPS is also the most practical model, in terms of patient's convenience of first visit timing and only once screening.

To be most accurate in cost-benefit analysis, the input values must be reliable. Accordingly, we used most reference ranges derived from our own population, in a large prospective study, since several parameters varies among geographical areas because of racial / biophysical factor and body size. As seen in the part I of the same project as this study, screening performance in detecting Down syndrome is significantly different between serum markers based on Caucasian reference range and Thai reference range; for example, false positive rate of $13.7 \%$ vs $7.7 \%$, respectively, for contingent screen. Therefore, this new study (part II of the same project [8]) used various input values derived from our own reference ranges. Likewise, though natural pregnancy loss is also slightly different from the western studies [13], we preferred using our own data.

Table 6 Benefits costs ratios (B/C) of various strategies from societal and government perspective at different costs of NIPS (Cost of Thai NIPS \$416.86 in 2016 and $\$ 277.90$ in 2019)

\begin{tabular}{|c|c|c|c|c|c|c|c|c|c|c|}
\hline \multirow[t]{2}{*}{ Strategies } & \multicolumn{5}{|c|}{ Societal Perspective } & \multicolumn{5}{|c|}{ Government Perspective } \\
\hline & $\$ 833.71$ & $\$ 694.76$ & $\$ 555.81$ & $\$ 416.86$ & $\$ 277.90$ & $\$ 833.71$ & $\$ 694.76$ & $\$ 555.81$ & $\$ 416.86$ & $\$ 277.90$ \\
\hline 1. No screening & 0 & 0 & 0 & 0 & 0 & 0 & 0 & 0 & 0 & 0 \\
\hline 2. Maternal age alone & 2.32 & 2.32 & 2.32 & 2.32 & 2.32 & 1.84 & 1.84 & 1.84 & 1.84 & 1.84 \\
\hline 3. STS alone & 3.49 & 3.49 & 3.49 & 3.49 & 3.49 & 1.99 & 1.99 & 1.99 & 1.99 & 1.99 \\
\hline 4. Independent screen (I-S) & 3.97 & 3.97 & 3.97 & 3.97 & 3.97 & 2.30 & 2.30 & 2.30 & 2.30 & 2.30 \\
\hline 5. C-S plus STS & 4.08 & 4.08 & 4.08 & 4.08 & 4.08 & 2.26 & 2.26 & 2.26 & 2.26 & 2.26 \\
\hline 6. Maternal age with NIPS & 1.59 & 1.87 & 2.28 & 2.91 & 4.24 & 0.31 & 0.38 & 0.47 & 0.62 & 1.32 \\
\hline 7. STS alone with NIPS & 3.05 & 3.26 & 3.50 & 3.78 & 4.35 & 0.91 & 1.02 & 1.16 & 1.35 & 1.81 \\
\hline 8. I-S with NIPS & 3.52 & 3.74 & 4.00 & 4.28 & 4.84 & 1.11 & 1.24 & 1.40 & 1.61 & 2.12 \\
\hline 9. C-S plus STS with NIPS & 3.68 & 3.83 & 4.00 & 4.19 & 4.52 & 1.31 & 1.43 & 1.56 & 1.73 & 2.09 \\
\hline 10. Universal NIPS & 0.80 & 0.94 & 1.14 & 1.46 & 2.63 & 0.16 & 0.19 & 0.24 & 0.31 & 0.66 \\
\hline
\end{tabular}


Current clinical practice in obstetrics has shifted the paradigm from a conventional prenatal approach based on invasive procedures, to non-invasive prenatal testing for some fetal aneuploidies via NIPS. Since the rapid spread around the world of prenatal diagnosis based on NIPS, it is time to start thinking how this cutting-edge technology might influence current practice of obstetrics in lowresource countries since NIPS will become available in low-resource countries in the foreseeable future [14]. Therefore, we included NIPS in CBA model in this study. Most developing countries have acute limitation of chromosome laboratory and no DS screening, though some countries have DS screening, mostly based on advanced maternal age. MSS is rarely available in the public sector. The main problem is that most poor women cannot access this kind of health care service which is usually available only in the private sector. Only rich couples undergo MSS and NIPS. In near future, DS will be a genetic condition of higher prevalence among those of lower socioeconomics means in comparison to their counterparts with higher socioeconomic means. Certainly, in developing countries, the percentages of NIPS uptake and serum screening are expected to be low, despite the fact that such models are more cost-beneficial than lack of screening or age-based screening as suggested.

Considering the best model for developing countries, several aspects must be taken into account: feasibility, expertise requirement, simplicity, costs of screening tests and invasive diagnosis, capacity in chromosome lab development etc. Note that this study did not include integrated tests, because of the high costs of double screenings with small additional detection rate. It also excluded NT and genetic sonogram, because of the need for high expertise, not practical in low resource settings. FTS alone was not suitable since many women had their first visit in late gestation. C-S plus STS was most effective but had higher costs due to the high rate of intermediate risk requiring STS and was complicated by counseling as well as anxiety during waiting for the final risk. Therefore I-S seems to be more attractive, though with slightly lower detection rate. Moreover, our findings surprisingly indicate that, even in low resource settings, incorporation of the expensive NIPS as a secondary test for high risk women is cost-beneficial, though NIPS as a primary screening is not cost-beneficial and not suitable for developing countries, unless its cost is markedly reduced. Challengingly, the poorer the country, the higher the need for the availability of NIPS, instead of karyotype laboratories. For example, in Thailand, we may need only one effective NIPS center to serve the entire country, whereas we may need a hundred cytogenetic laboratories, including intensive training of more than 1000 technicians to cover the screening of all the 800,000 Thai pregnant women each year. To date, our country could not perform chromosome studies more than 20,000 cases per year. Therefore, NIPS as a secondary screening is more feasible and more cost-effective to serve an entire country, without the overload of amniocentesis and chromosome laboratories, especially when the cost of NIPS reduces. However, although the CBA derived from this study may not be applied to many other countries with lower or higher resource setting than Thailand, it can serve as a study model for other countries.

Because health care resources are limited, CBA-based modeling must be used to guide resource allocation. Since the current practice using conventional or age-based screening would be the least costly model, decision-makers might tend to refrain from implementing NIPS in national health care. However, our CBA indicates that the benefits of NIPS should not be underestimated. In addition to high accuracy, ease to understand, and safe option, the need for less number of experts and chromosome labs must be taken into account. Its implementation could directly facilitate the ultimate goal of the national program for prenatal control of fetal DS. The cost-benefit of NIPS is directly related to its costs and the estimated costs of taking care of a life time of DS. Thus, investments in NIPS would in fact be outweighed by a concurrent decrease in health care and societal costs associated with DS. Note that if we use Caucasian reference ranges of MSS, the false positive rate is very high, leading to a substantial burden of invasive diagnosis as well as fetal loss or expensive NIPS and possibly no costbenefit. Such effects may not be so serious for the payer perspective but are very serious for societal and government perspectives. Therefore, we strongly recommend the development of the normal reference ranges of the intended population for the formation of a national policy.

The strengths of this study are as follows: 1) CBA was based on the strategy effectiveness data and event probabilities derived from the same population and real situations as well as consideration of the proportion of women with late visits of prenatal care. 2) The costs of all tests and medical or non-medical care based on real situations of developing countries like Thailand.

The weaknesses of this study are as follows: 1) CBA did not include payer perspective. 2) The structures and inputs of the decision-analytic model in this study were primarily focused on our national health care. Thus, the results might not be perfectly accurate for other countries' strategies. However, we believe that this could probably be a model for several developing countries especially many parts of Asia. 3) Though I-S with NIPS is most cost-beneficial, its true feasibility of implementation has not yet been explored. 4) Our CBA was derived from Thailand, these data might not perfectly be translated to other developing countries due to uncertainties in uptake or variations in the purchasing power and currency adjustment (World Bank data). Therefore, our results must be cautiously interpreted when applied for 
other developing countries. 5) This study focused exclusively on DS, did not address the cost issues of the bigger picture. On economic view, DS is only a small part of complete chromosomal and copy number variant abnormalities that can produce as much personal and financial burdens to any population. 6) Indirect cost of taking care of DS might not be perfectly validated. For example, incremental cost savings due to less chance of DS patients to attend university or get married, among many other potential social factors were not incorporated in analysis. As such, our analyses might be positively skewed toward the benefits of prenatal screening.

\section{Conclusion}

1) The challenging finding is that, even in low resource settings, I-S with NIPS seems to be most cost-beneficial. Women of all socio-economic levels should have an equal chance to access this facility. 2) The strong impact factors of cost-benefit include cost of NIPS, cost of taking care of a DS child and false positive rate of MSS. 3) Our findings emphasize that the most expensive public policy is to have no screening. Additionally, cost-benefit can be much varied at different NIPS costs. It can change enormously based on changing costs of individual elements, miscalculations in percentage of choices people make, etc.

\section{Abbreviations}

CBA: Cost-benefit analysis; CPI: Consumer price index; C-S: Contingent first trimester screening; DS: Down syndrome screening; FTS: First trimester screening; I-S: Independent first and second trimester screening; MSS: Maternal serum screening; NIPS: Non-invasive prenatal test; STS: Second trimester screening; WTP: Willingness to pay

\section{Acknowledgements}

Not Applicable.

\section{Authors' contributions}

$\mathrm{CW}$ : contributed to the conception, design of the research and administration of the project, and drafting / revising the manuscript; PB: contributed to the conception, economical analysis and revising the manuscript; WH: contributed to the conception, economical analysis and revising the manuscript; AS: contributed to the conception, economical analysis and revising the manuscript; $\Pi$ : contributed to the conception, design of the research and revising the manuscript. All authors contributed to the interpretation and writing of the paper and approved the final version.

\section{Funding}

Chiang Mai University Research Fund (CMU-2562). The funder had no any role in the design of the study and collection, analysis, and interpretation of data and in writing the manuscript.

\section{Availability of data and materials}

Data is available through the corresponding author. The data set is filed at the Chiang Mai University Thailand. The data set has not been deposited in a public repository due to the confidential nature of patient data and issues with confidentially and anonymity in the small, rural community we were working in.

\section{Ethics approval and consent to participate}

This study received ethnical approval from the institute review boards of Faculty of Medicine, Chiang Mai University (Ethics Committee 4; Research ID 4981).
All participants signed Informed Consent Forms.

Consent for publication

Not Applicable.

\section{Competing interests}

The authors declare that they have no competing interests.

\section{Author details}

${ }^{1}$ Department of Obstetrics and Gynecology, Faculty of Medicine, Chiang Mai University, Chiang Mai 50200, Thailand. 'Faculty of Economics, Chiang Mai University, Chiang Mai, Thailand.

Received: 24 January 2019 Accepted: 31 October 2019

Published online: 27 November 2019

\section{References}

1. Wald NJ, Rodeck C, Hackshaw AK, Walters J, Chitty L, Mackinson AM. First and second trimester antenatal screening for Down's syndrome: the results of the serum, urine and ultrasound screening study (SURUSS). J Med Screen. 2003;10:56-104

2. Waitzman NJ, Scheffler RM, Romano PS. The cost of birth defects: estimates of the value of prevention: University Press of America; 1996.

3. Pattanaphesaj J, Tonmukayakul U, Teerawattananon Y. Cost-benefit analysis of prenatal screening and diagnosis for Down syndrome in Thailand. J Health Sci. 2012;21:667.

4. Neyt M, Hulstaert F, Gyselaers W. Introducing the non-invasive prenatal test for trisomy 21 in Belgium: a cost-consequences analysis. BMJ Open. 2014;4: e005922.

5. Odibo AO, Stamilio DM, Nelson DB, Sehdev HM, Macones GA. A costeffectiveness analysis of prenatal screening strategies for Down syndrome. Obstet Gynecol. 2005;106:562-8.

6. Ohno M, Caughey A. The role of noninvasive prenatal testing as a diagnostic versus a screening tool--a cost-effectiveness analysis. Prenat Diagn. 2013:33:630-5.

7. Walker BS, Nelson RE, Jackson BR, Grenache DG, Ashwood ER, Schmidt RL. A cost-effectiveness analysis of first trimester non-invasive prenatal screening for fetal Trisomies in the United States. PLoS One. 2015;10:e0131402.

8. Wanapirak C, Piyamomgkol W, Sirichotiyakul S, Tongprasert F, Srisupundit K, Luewan $S$, et al. Fetal Down syndrome screening models for developing countries; Part I: Effectiveness of Maternal Serum Screening. BMC Health Serv Res. 2019; [Epub ahead of print].

9. Day SM, Strauss DJ, Shavelle RM, Reynolds RJ. Mortality and causes of death in persons with Down syndrome in California. Dev Med Child Neurol. 2005: 47:171-6.

10. Kucik JE, Shin M, Siffel C, Marengo L, Correa A. Trends in survival among children with Down syndrome in 10 regions of the United States. Pediatrics. 2013:131:e27-36.

11. Kageleiry A, Samuelson D, Duh MS, Lefebvre P, Campbell J, Skotko BG. Outof-pocket medical costs and third-party healthcare costs for children with Down syndrome. Am J Med Genet A. 2017;173:627-37.

12. Committee on Practice Bulletins-Obstetrics CoG, and the Society for Maternal-Fetal Medicine. Practice Bulletin No. 163 Summary: Screening for Fetal Aneuploidy. Obstet Gynecol. 2016;127:e123-37.

13. Savva GM, Morris JK, Mutton DE, Alberman E. Maternal age-specific fetal loss rates in Down syndrome pregnancies. Prenat Diagn. 2006;26:499-504.

14. Ventura W, Nazario-Redondo C, Sekizawa A. Non-invasive prenatal diagnosis from the perspective of a low-resource country. Int J Gynaecol Obstet. 2013; 122:270-3.

\section{Publisher's Note}

Springer Nature remains neutral with regard to jurisdictional claims in published maps and institutional affiliations. 